\title{
Multi-modality assessment and role of left atrial function as an imaging biomarker in cardiovascular disease
}

\author{
Aseel Alfuhied $^{1,2} \cdot$ Prathap Kanagala $^{1,3} \cdot$ Gerry P. McCann $^{1} \cdot$ Anvesha Singh $^{1}(\mathbb{0}$
}

Received: 15 May 2021 / Accepted: 14 June 2021 / Published online: 24 June 2021

(c) The Author(s) 2021

\begin{abstract}
The left atrium (LA) plays a vital role in maintaining normal cardiac function. LA volume and function have been utilised as important imaging biomarkers, with their prognostic value demonstrated in multiple cardiac conditions. More recently, there has been a sharp increase in the number of publications utilising LA strain by echocardiography and cardiac magnetic resonance (CMR) imaging. However, little is known about its prognostic value or reproducibility as a technique. In this review, we aim to highlight the conventional and novel imaging techniques available for LA assessment, using echocardiography and CMR, their role as an imaging biomarker in cardiovascular disease, the reproducibility of the techniques and the current limitations to their clinical application. We identify a need for further standardisation of techniques, with establishment of 'normal' cut-offs before routine clinical application can be made.
\end{abstract}

Keywords Left atrium $\cdot$ Echocardiography $\cdot$ Cardiac magnetic resonance $\cdot$ Strain

$\begin{array}{ll}\begin{array}{l}\text { Abbreviations } \\ \text { CMR }\end{array} & \begin{array}{l}\text { Cardiovascular magnetic } \\ \text { resonance } \\ \text { Coefficient of variance } \\ \text { CoV }\end{array} \\ \text { HF } & \text { Leart failure } \\ \text { LA } & \text { Left atrium atrial emptying fraction } \\ \text { LAEF } & \text { Left atrial strain/strain rate at } \\ \text { LAS/SR_bp } & \text { booster pump phase } \\ & \text { Left atrial strain/strain rate at } \\ \text { conduit phase }\end{array}$

Anvesha Singh

as707@leicester.ac.uk

Aseel Alfuhied

aa1108@leicester.ac.uk

Prathap Kanagala

pkk12@leicester.ac.uk

Gerry P. McCann

gpm12@leicester.ac.uk

1 Department of Cardiovascular Sciences, University of Leicester, National Institute for Health Research (NIHR)

Leicester Biomedical Research Centre, Leicester, UK

2 King Saud Bin Abdulaziz University for Health Sciences, Riyadh, Saudi Arabia

3 Aintree University Hospital, Liverpool, UK

\section{LAS/SR_r}

$\mathrm{LAV}(\max / \mathrm{min} / \mathrm{pre}-\mathrm{A})$

TTE

\section{Introduction}

Traditionally left ventricular (LV) function has been the key imaging marker of prognosis in heart disease, and LV ejection fraction (EF) cut-off points have been used in heart failure (HF) guidelines to guide therapy[1,2]. Left atrial (LA) volume has also been recognised for its association with adverse cardiovascular outcomes in the general population [3], in those at risk of developing cardiovascular disease [4] and in multiple cardiac conditions [5, 6]. LA volume indexed to body surface area forms an integral part of LV diastolic function assessment [7] and is an essential component for the diagnostic criteria for heart failure with preserve ejection fraction (HFpEF), previously referred to as diastolic heart failure [8-10]. LA function has also attracted considerable attention as a cardiovascular imaging biomarker due to its prognostic importance [11-14] and because functional abnormalities often precede adverse LA structural remodelling and overt clinical disease [9, 15-19]. 
Currently, LA function is routinely evaluated using traditional 2D echocardiography derived volumetric measurements [20]. 2D echocardiography however, underestimates LA volumes compared to cardiovascular magnetic resonance (CMR) imaging, which is the gold standard for volumetric quantification [21]. LA volumes and function can also be assessed using cardiac computed tomography (CT) [22, 23] however, it is a source of ionizing radiation exposure and is not routinely utilised in clinical practice, and will not be the focus of this article. LA deformation measurement is a relatively recent technique that tracks LA phasic function and allows early detection of subclinical cardiac dysfunction, even in those with normal LA size [19]. Such techniques could overcome the limitations of volumetric assessment, which relies on geometric assumptions and loading conditions [24]. Moreover, LA strain may play an important role in classifying the degree of LV diastolic dysfunction [25], potentially eliminating the complexity in diastolic dysfunction assessment. The aim of this review is to highlight the current non-invasive imaging techniques available on echocardiography and CMR for assessing LA function, and their prognostic utility.

\section{Left atrial phasic function}

LA function consists of 3 phases (Fig. 1): reservoir, conduit and booster pump phases, which are responsible for the transformation of the continuous pulmonary venous return flow into intermittent LV filling [26]. During ventricular systole and isovolumetric relaxation, the LA acts as a 'reservoir' receiving blood flow from the pulmonary veins due to a decrease in filling pressure, leading to an increase in LA size. The conduit phase occurs during early diastole, and reflects passive emptying of the LA into the LV, governed by the transient LA to LV pressure gradient. Finally, booster pump (contraction), for those in sinus rhythm, occurs during late diastole resulting in active LA emptying attributed to the Frank-Starling mechanism, afterload and myocardial contractility [27-29].

\section{LA dysfunction}

LA dysfunction has a marked influence on LV filling and cardiac output and is associated with the future development of HF [9]. LA reservoir function is governed by LA compliance, but is influenced by atrial contraction and relaxation, and LV systolic shortening. Thus, a decrease in atrial compliance and relaxation ability in the presence of LA stiffness causes LA reservoir dysfunction, whilst a reduction in the apical displacement of the mitral valve due to LV longitudinal dysfunction reduces passive LA stretch [30,31].

LA conduit dysfunction results from an impairment in the atrioventricular pressure gradient mainly caused by LV diastolic dysfunction, impaired LV relaxation and increased stiffness that diminishes passive filling. With conduit impairment, the LA compensates by increasing booster pump function, which can be seen during the early stages of hypertensive heart disease [32]. However, this compensation is typically absent in patients with HFpEF due to chronically elevated LV filling pressures [33].
Fig. 1 Left atrial function. Left atrial (LA) phasic function and the temporal relationship between LA volume and electrocardiogram (ECG). Pre- $\mathrm{A}=$ pre atrial contraction, $\mathrm{MV}=$ mitral valve, $\mathrm{LV}=$ left ventricle. Red arrows represent blood flow, blue arrows represent myocardial deformation

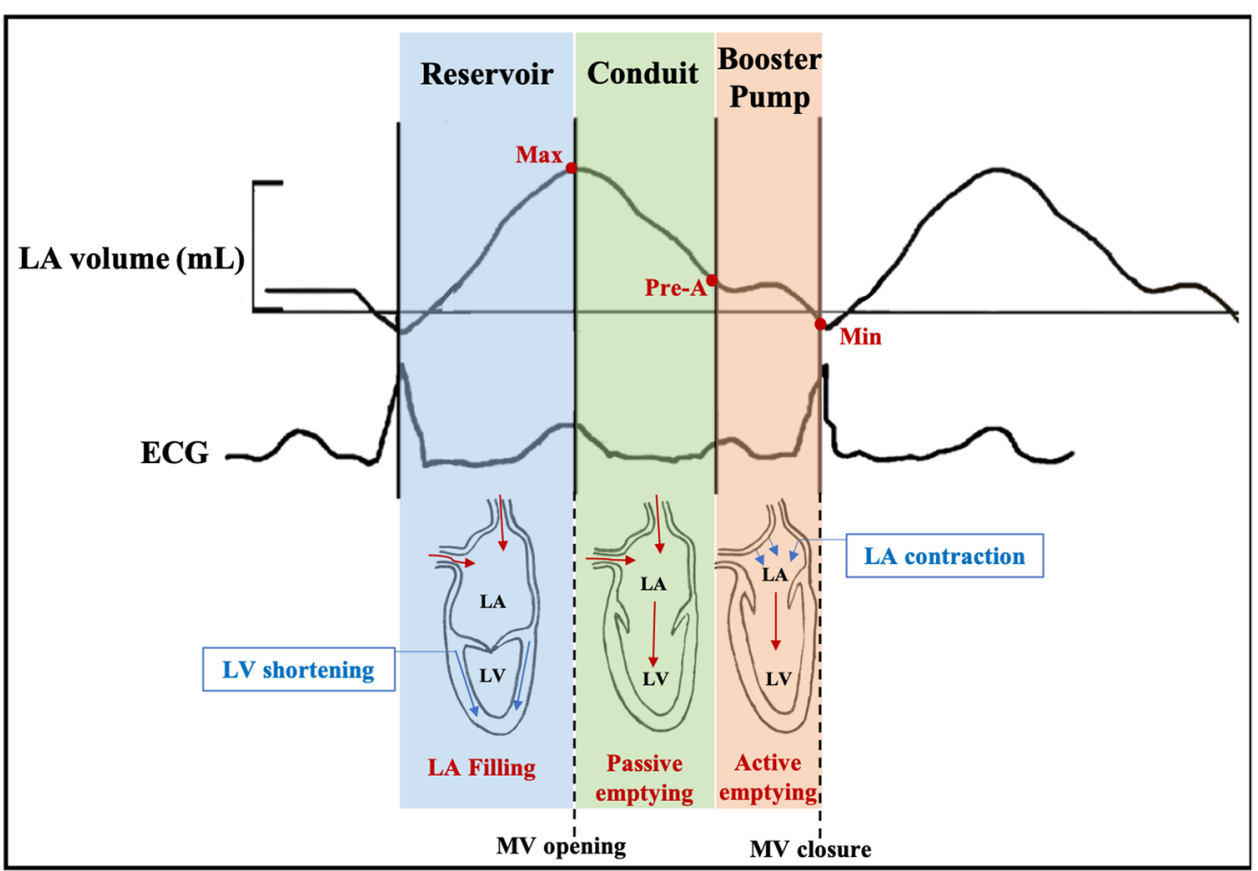


LA mechanical dysfunction precedes LA structural remodelling. Excessive increase in LA volume and pressure lead to histological changes such as an increase in the cardiac myocyte length, which results in progressive dilatation of the atria, myocyte hypertrophy, and fibrosis [32, 34, 35]. Moreover, LA dilatation is associated with atrial fibrillation (AF) [36]. LA booster pump dysfunction occurs in the event of abnormal LA contractility, pre-atrial contraction volume (preload), or LV end-diastolic pressure (afterload), whilst $\mathrm{AF}$ results in the absence of the LA booster pump function [37].

\section{LA functional assessment techniques}

\section{Volumetric assessment}

LA phasic function can be assessed by quantifying LA volume (LAV) in three phases across the cardiac cycle: maximum (max), minimum (min) and pre-atrial (pre-a) contraction volumes (Supplemental Figure-1). Emptying fraction (EF) is calculated corresponding to the three LA phases: reservoir function $(\mathrm{LA}$ total $\mathrm{EF}=[(\mathrm{LAVmax}-\mathrm{LAVmin}) /$ LAVmax $] \times 100 \%)$ and $(\mathrm{LA}$ expansion index $==[(\mathrm{LAVmax}$ - LAVmin)/LAVmin] $\times 100 \%$ ) [38], conduit function (LA passive $\mathrm{EF}=[(\mathrm{LAV}$ max $-\mathrm{LAV}$ pre-A $) / \mathrm{LAV} \max ] \times 100 \%)$ and booster pump function (LA active $\mathrm{EF}=[(\mathrm{LAV}$ preA- LAVmin)/LAVpre-A] $\times 100 \%$ ) [16]

LA volume is quantified on 2D-Transthoracic echocardiography (TTE) by either the biplane area length or biplane modified Simpson's discs method using 4- and 2-chamber images [20] (Fig. 2A). Both these methods however underestimate LA volumes compared to CMR due to variation in the spherical shape of the LA [21]. LA volumes by 3D-TTE (Fig. 2B) show better correlation with CMR than with 2D-TTE and exhibit tighter limits of agreement on Bland-Altman analysis, albeit only LAVmax showed limits of agreement within 10\% [39]. On the contrary, a recent retrospective study including 56 patients in sinus rhythm showed only modest correlation and limits of agreement more than $10 \%$ for LAVmax and total EF when comparing 3D-TTE with CMR [40]. However, fully automated software was used to quantify LA volume by 3D-TTE, which may in part explain the poorer agreement.

In addition to the biplane area length method, CMR allows LA quantification using the short-axis cine stack, overcoming geometric assumptions by tracing the LA endocardial borders from successive slices across the LA length based on Simpson's method of discs (Fig. 2C and D). LAEF by short-axis method demonstrated superior test-retest reproducibility in comparison to the biplane arealength method on CMR (CoV 4-19\% and CoV 7.9-24\% respectively), however, this study only included healthy volunteers and a small sample size $(n=4)$ [41]. The same study demonstrated no significant difference in LA volumes and EF between the two methods using steady-state free precession (SSFP) cines. Similarly, the mean LA volume was not significantly different between the two methods using SSFP images and showed excellent correlation $(\mathrm{r}=0.92$; $\mathrm{p}<0.001)$, with modest agreement $(-0.6 \mathrm{ml}$ bias and $(+23.5$, $-24.7 \mathrm{ml})$ limits of agreement) in AF patients $(\mathrm{n}=81)$ [42]. In another study using the gradient-echo sequence (TrueFISP), while LA volumes were significantly higher with the biplane area-length method, there was no significant
Fig. 2 Imaging assessment of left atrial function. LA volumetric assessment using Transthoracic echocardiography (TTE) include biplane disk method (A) and 3D method(B), and using CMR include biplane area length method $(\mathbf{C})$, and short axis stack method (D). LA deformation assessment using Speckle tracking echocardiography $(\mathbf{E})$, and feature tracking on CMR (F). An example of LA strain curve and the measurements corresponding to LA phases $(\mathbf{G})$. LAS_r $=$ LA strain at reservoir, LAS_cd $=\mathrm{LA}$ strain at conduit, LAS_bp $=$ LA strain at booster-pump phase

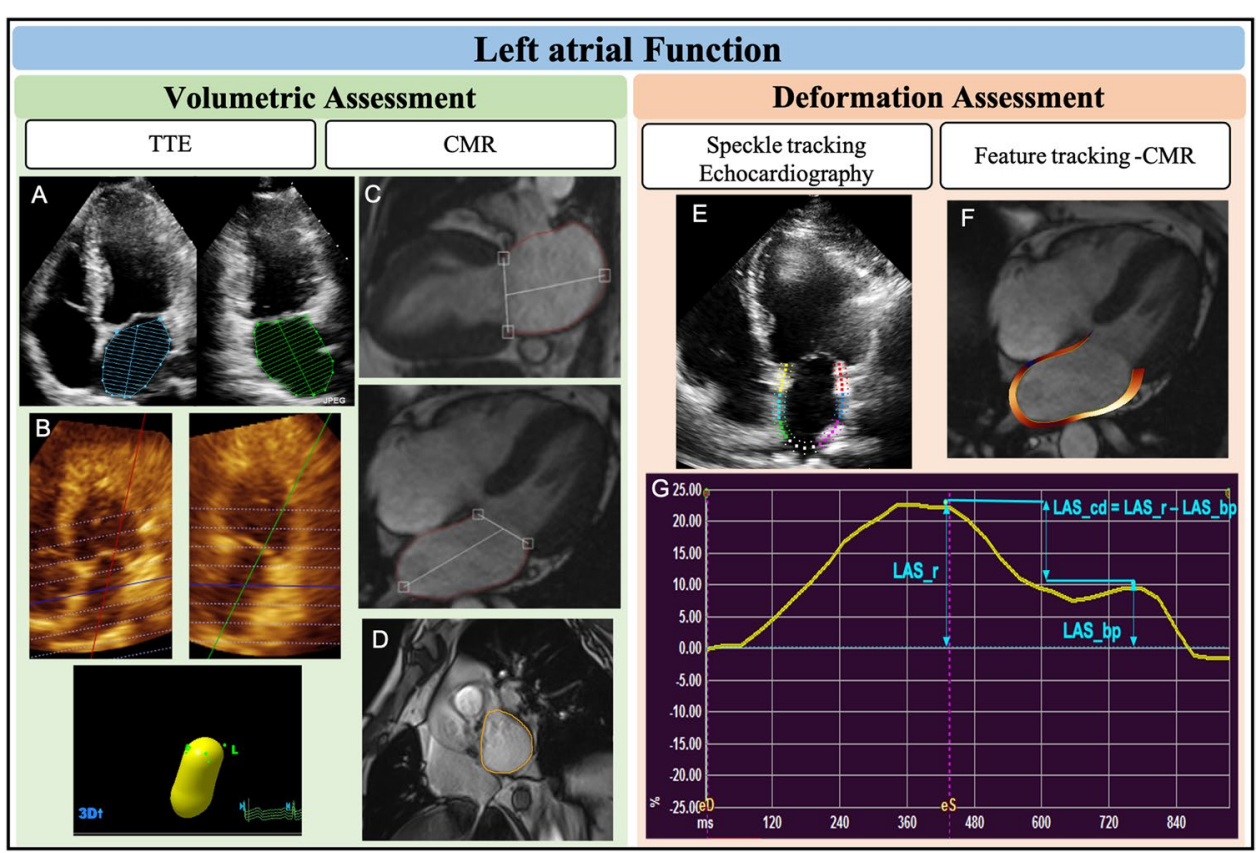


difference in LAEF between the two methods in both sinus rhythm $(n=15)$ and AF $(n=18)$ subjects [43]. Thus, despite the superior reproducibility of the short-axis method, the area-length method allows a practical and less time-consuming assessment of LA volume and function using routinely acquired 4- and 2-chamber SSFP cines, without the need for additional breath-holds for patients to acquire the short-axis cine stack.

\section{LA deformation assessment}

Non-invasive imaging modalities have assessed LA deformation for initial diagnosis [25, 44-47], prognostic assessment [48-51], and evaluation of treatment response across different disease states [52-55]. Cardiac deformation analysis using strain and strain rate (SR) imaging allows early detection of pre-clinical cardiac disease.

Strain is an angle independent measurement that reflects the percentage of myocardial deformity (changing length) throughout the cardiac cycle. Strain is calculated as:

$\Delta L / L 0$

where $\Delta \mathrm{L}$ is the change in myocardial length, and L0 is the original length of the myocardium.

$\mathrm{SR}$ is myocardial deformity over time (the speed of myocardial deformation) [56]. Although LA strain (LAS) is preload dependent, loading has less effect on LA strain than LA volume [24], while LA strain rate (LASR) is less load-dependent than strain [57]. Both TTE and CMR use post-processing image analysis software to assess LAS and LASR, using routinely acquired 2-chamber and 4-chamber cine images. LA endocardial borders are manually traced and propagated throughout the cardiac cycle using speckle tracking in TTE or feature tracking in CMR (Fig. 2E and F).

\section{Speckle Tracking Echocardiography (STE)}

Tissue Doppler imaging (TDI) is an image acquisition that is used traditionally to estimates strain in TTE. However, it depends on angle of insinuation and provides regional evaluation of LA function [58, 59]. STE technique is a post-processing algorithm that quantifies LA deformation by tracking the motion of speckles within the whole myocardium through the cardiac cycle, using standard 2D echocardiography B-mode images [60](Fig. 2E). Strain and SR curves are generated after tracing the LA endocardium during systole and diastole. It is recommended to use non-foreshortened views of the LA in order to obtain adequate strain values, as well as the use of ventricular end-diastole as the time reference frame of zero strain [61].

The main limitation of STE is the need for high image quality and frame rates in order to obtain optimal endocardial tracing, which can be challenging for the LA, as it is in the far-field, and windows are affected by patient characteristics such as obesity and airways disease. This phenomenon is particularly evident in obese individuals whereby $21 \%$ of the such patients were excluded from STE analysis due to inadequate image quality [62].

\section{Feature tracking CMR}

Feature tracking (FT) is a post-processing strain assessment technique that uses standard CMR cine images for strain analysis (Figs. 2F and G). The analysis is performed offline using dedicated software which provides a more practical way by allowing shorter scan times. The general principle of FT is similar to STE, where features within the myocardium are tracked through the cardiac cycle. Strain assessment by CMR has several advantages over TTE such as improved spatial resolution, high signal and contrast ratio (between blood pool and myocardium), unlimited windows and clearer myocardial definition, enabling optimal tracking. Furthermore, with adequate planning, there is less propensity for foreshortened images than TTE.

Similar strain curves are generated by both TTE and CMR techniques (Fig. 2G). LAS/LASR can be measured for the three LA phases [61]: reservoir function (LAS_r and LASR_r), conduit function (LAS_cd and LASR_cd) and contraction booster-pump ( LAS_bp and LASR_bp). LAS_cd can be calculated as: LAS_cd = LAS_r - LAS_bp.

\section{Reference values in healthy adults}

\section{TTE}

In a population study including 371 subjects, the normal values of LA function using TomTec 2D analysis were: total LAEF $68.5 \pm 5.3$, passive EF $43.0 \pm 10.3$ and active EF 43.1 \pm 9.4 , while the total LAEF using 3D-TTE is $57.3 \pm 4.9[63]$. In a meta-analysis for normal LAS parameters by STE [64], 40 studies (2,542 patients) were included for reservoir strain, 14 studies (805 patients) for conduit and 18 studies (1,005 patients) for contractile strain, with an age range of 25-68 years. Most of the studies $(n=34)$ used a GE echocardiography platform (EchoPac). The normal ranges were: $27.6 \%$ to $59.8 \%$ for reservoir, $15.7 \%$ to $33.4 \%$ for conduit and $14.0 \%$ to $25.0 \%$ for booster pump strain, without significant difference between men and women. Studies on LASR normal values are limited. One study including 329 healthy adults reported the normal range of LASR at booster pump only, which was $-2.11 \pm 0.61 \mathrm{~s}^{-1}[65]$. 


\section{CMR}

Normal ranges for LAEF, LAS and LASR using CMR are shown in Table 1. With age, LA reservoir and conduit functions by volumetric assessment decrease, while booster pump function increases [66]. The LA appendage was included while the pulmonary veins were excluded from the analysis in most studies [67, 68]. Only one study focused on normal values of LA strain and strain rate by FT on 112 healthy volunteers, with a median age of 42 (IQR 30-53) years (64). The study showed no significant difference between genders in all strain and strain rate parameters. LA contractile function increased significantly with age for both strain and strain rate, while the LA conduit function decreased.

Overall, LAEF values are lower on CMR compared to TTE, but LAS values seem to be closer together (Fig. 3). The variation in values caused by vendors and imaging modality however, raises important questions regarding the validity and generalisability of the technique. Reference ranges require further validation by studying larger cohorts, and considerations of the possible influence of field strength and vendors. LASR by STE and both LAS and LASR by FTCMR have no standardised reference ranges to date due to limited published literature on normal ranges and the variability mentioned above.

\section{Prognostic value of volumetric LA function}

The prognostic value of LA volume $[3-6,69,70]$ and size [71] is well established in multiple cardiovascular conditions. TTE studies have shown LA dysfunction, measured as a decrease in LAEF or LA function index (LAFi), to be an independent predictor of all-cause mortality or HF hospitalization in coronary artery disease $[11,72]$, heart failure with reduced ejection fraction (HFrEF) $[73,74]$ and AF[75] (Table 2). LAFi is calculated as: (LA emptying fraction $\times$ left ventricular outflow tract velocity time integral)/LA end-systolic volume index.

LAEF by CMR was recognised as a subclinical cardiac biomarker, with a decrease in LA total EF being an independent predictor of all-cause mortality and AF incidence in the general population [76, 77]. In addition, a decrease in LA active EF in patients with hypertension and no cardiovascular symptoms showed a strong predictive value for adverse cardiac events including MI, HF hospitalization and death [78].

A recent observational study demonstrated that CMRderived LAEF using the biplane area length method was lower in patients with HFpEF compared to controls [12], and was associated with an increased risk of the composite endpoint of death and or HF hospitalization. Another study of
664 patients with HF, irrespective of LVEF, showed increasing LAEF to be independently associated with survival (HR for $10 \%$ change: $0.81,95 \%$ CI: $0.73-0.90$ ), P $\leq 0.001$ ), whereas, decreasing LAEF and increasing age predicted the incident AF [14].

\section{Prognostic value of LA deformation}

\section{Speckle tracking echocardiography (STE)}

LAS by STE shows a promising, non-invasive approach to predicting changes in LV filling pressure. Recent studies show that LAS at reservoir phase predicts elevated LV enddiastolic pressure in patients with coronary artery disease [79] and patients with normal LVEF [45]. Another study that included 76 patients referred for left heart catheterization demonstrated LA reservoir strain to be an independent predictor of LV filling pressure, with a cutoff value of $\mathrm{LASr}<20 \%$ being optimal to detect elevated LV filling pressure (area under the curve 0.76) [47].

The literature highlighted the prognostic utility of LA strain as a sensitive marker to assess subclinical cardiac dysfunction $[19,80]$. A recent review concluded LA strain dysfunction might precede the impairment in LV deformation in valvular disease, as it was associated with a decrease in functional capacity, even when LV global longitudinal strain was preserved, and might have a role in guiding early intervention [81]. A prospective study on 312 subjects in sinus rhythm, with known cardiovascular diseases [82], showed that LA strain during the reservoir phase using STE independently predicts cardiovascular events including AF, HF and mortality with high diagnostic accuracy (cut-off for LASr $<19 \%$, area under the curve 0.83). LA strain showed an ability to differentiate between HF categories, independent of LA volume and other diastolic function parameters [83]. HFpEF studies have also shown LA reservoir dysfunction by strain to be independently associated with adverse outcomes and HF hospitalization [84-86].

LAS_r has also been used in calculating a surrogate of LA stiffness (calculated as the ratio of E/e' to LAS_r) [52, 87, 88]. LA stiffness was a strong predictor of adverse outcomes (death and HF hospitalization) in a study of $215 \mathrm{HF}$ patients [87].

\section{Feature tracking CMR}

Studies assessing the prognostic value of LA strain by FTCMR are limited. In the Multi-Ethnic Study of Atherosclerosis (MESA), LA dysfunction by FT preceded HF incidence in the asymptomatic general population, and LA reservoir strain was an independent predictor of HF[9]. The same study also concluded that LA reservoir strain independently 
Table 1 The normal ranges for LA function parameters by CMR in population Studies

\begin{tabular}{|c|c|c|c|c|c|c|}
\hline $\begin{array}{l}\text { First Author, year } \\
\text { (Ref. \#) }\end{array}$ & $\begin{array}{l}\text { Population } \\
\text { (Male, Female) }\end{array}$ & Age & $\begin{array}{l}\text { Scanner } \\
\text { (Image analysis } \\
\text { software) }\end{array}$ & $\begin{array}{l}\text { LA function param- } \\
\text { eter }\end{array}$ & $\begin{array}{l}\text { Normal range } \\
(\text { Mean } \pm S D)\end{array}$ & Comments \\
\hline $\begin{array}{l}\text { Hudsmith et al., } \\
2005 \text { [67] }\end{array}$ & $\begin{array}{l}\mathrm{HV}(\mathrm{n}=108) \\
(63 \mathrm{M}, 45 \mathrm{~F})\end{array}$ & $\begin{array}{l}38 \pm 12 \text { years } \\
\text { (range } 21-68)\end{array}$ & $\begin{array}{l}\text { CMR } 1.5 \mathrm{~T} \\
\text { (Argus Siemens) }\end{array}$ & $\begin{array}{l}\text { Volumetric (\%): } \\
\text { Total EF }\end{array}$ & $54 \pm 12 \%$ & $\begin{array}{l}\text { Biplane area length } \\
\text { method } \\
\text { LAA included and } \\
\text { pulmonary veins } \\
\text { excluded from the } \\
\text { analysis } \\
\text { No significant dif- } \\
\text { ference between } \\
\text { gender }\end{array}$ \\
\hline $\begin{array}{l}\text { Maceira et al., } 2016 \\
\text { [66] }\end{array}$ & $\begin{array}{l}\mathrm{HV}(\mathrm{n}=120) \\
(60 \mathrm{M}, 60 \mathrm{~F})\end{array}$ & $49 \pm 17$ years & $\begin{array}{l}\text { CMR } 1.5 \mathrm{~T} \\
\text { (3D-CMRTools, } \\
\text { Cardiovascular } \\
\text { Imaging Solu- } \\
\text { tions) }\end{array}$ & $\begin{array}{l}\text { Volumetric }(\%) \text { : } \\
\text { Total EF } \\
\text { Passive EF } \\
\text { Active EF }\end{array}$ & $\begin{array}{l}59 \pm 5.8 \% \\
35 \pm 6 \% \\
36 \pm 6.8 \%\end{array}$ & $\begin{array}{l}\text { Data generated from } \\
\text { 3D-modelling } \\
\text { LAA included and } \\
\text { pulmonary veins } \\
\text { excluded } \\
\text { With age LA reser- } \\
\text { voir and conduit } \\
\text { functions decreased } \\
\text { while the booster } \\
\text { pump function } \\
\text { increased } \\
\text { Females had sig- } \\
\text { nificantly higher } \\
\text { conduit function } \\
\text { than males }\end{array}$ \\
\hline $\begin{array}{l}\text { Petersen et al., } 2017 \\
\text { [104] }\end{array}$ & $\begin{array}{c}\mathrm{HV}(\mathrm{n}=795) \\
(363 \mathrm{M}, 432 \mathrm{~F})\end{array}$ & $\begin{array}{l}59 \pm 7 \text { years (range } \\
45-74)\end{array}$ & $\begin{array}{l}\text { CMR 1.5 T } \\
\text { (Cvi42, version } \\
5.1 .1)\end{array}$ & $\begin{array}{l}\text { Volumetric (\%): } \\
\text { Total EF }\end{array}$ & $60 \pm 7 \%$ & $\begin{array}{l}\text { Caucasian ethnicity } \\
\text { only from the UK } \\
\text { biobank } \\
\text { Biplane area length } \\
\text { method } \\
\text { No significant dif- } \\
\text { ference between } \\
\text { gender }\end{array}$ \\
\hline $\begin{array}{l}\text { Peng et al., } 2018 \\
\text { [105] }\end{array}$ & $\begin{array}{l}\mathrm{HV}(\mathrm{n}=150) \\
(75 \mathrm{M}, 75 \mathrm{~F})\end{array}$ & $43 \pm 12$ years & $\begin{array}{l}\text { CMR } 1.5 \mathrm{~T} \text { or } 3.0 \mathrm{~T} \\
\text { (Medis, Qmass and } \\
\text { Qstrain) }\end{array}$ & $\begin{array}{l}\text { Volumetric }(\%) \text { : } \\
\text { Total EF } \\
\text { Strain }(\%) \text { : } \\
\text { Reservoir Strain }\end{array}$ & $\begin{array}{l}58 \pm 9 \% \\
32.8 \pm 9.2\end{array}$ & $\begin{array}{l}\text { Two sites: bSSFP and } \\
\text { BTFE sequences } \\
\text { used respectively in } \\
\text { each site } \\
\text { Volume by Biplane } \\
\text { area length method } \\
\text { Strain 2- and 4-cham- } \\
\text { ber, excluding } \\
\text { pulmonary veins } \\
\text { and LAA } \\
\text { No significant dif- } \\
\text { ference between } \\
\text { gender } \\
\text { Reservoir strain } \\
\text { reduced signifi- } \\
\text { cantly with age }\end{array}$ \\
\hline
\end{tabular}


Table 1 (continued)

\begin{tabular}{|c|c|c|c|c|c|c|}
\hline $\begin{array}{l}\text { First Author, year } \\
\text { (Ref. \#) }\end{array}$ & $\begin{array}{l}\text { Population } \\
\text { (Male, Female) }\end{array}$ & Age & $\begin{array}{l}\text { Scanner } \\
\text { (Image analysis } \\
\text { software) }\end{array}$ & $\begin{array}{l}\text { LA function param- } \\
\text { eter }\end{array}$ & $\begin{array}{l}\text { Normal range } \\
(\text { Mean } \pm \mathrm{SD})\end{array}$ & Comments \\
\hline $\begin{array}{l}\text { Truong et al., } 2019 \\
\text { [68] }\end{array}$ & $\begin{array}{l}\mathrm{HV}(\mathrm{n}=112 \\
(45 \mathrm{M}, 67 \mathrm{~F})\end{array}$ & $\begin{array}{l}42 \text { years (median) } \\
\text { IQR } 30-53\end{array}$ & $\begin{array}{l}\text { CMR } 1.5 \mathrm{~T} \\
\text { 2D-FT } \\
\text { (Cvi42, version } \\
5.3 .4)\end{array}$ & $\begin{array}{l}\text { Volumetric }(\%) \text { : } \\
\text { Total EF } \\
\text { Passive EF } \\
\text { Active EF } \\
\text { Strain }(\%) \text { : } \\
\text { Reservoir Strain } \\
\text { Conduit Strain } \\
\text { Contractile Strain } \\
\text { Strain rate }\left(\mathrm{s}^{-1}\right) \text { : } \\
\text { Reservoir SR } \\
\text { Conduit SR } \\
\text { Contractile SR }\end{array}$ & $\begin{array}{l}58.8 \pm 3.7 \\
39.2 \pm 6.2 \\
31.9 \pm 6.1 \\
39.13 \pm 9.27 \\
25.15 \pm 8.34 \\
13.99 \pm 4.11 \\
1.93 \pm 0.54 \\
-2.13 \pm 0.69 \\
-2.04 \pm 0.61\end{array}$ & $\begin{array}{l}\text { Volumetric by biplane } \\
\text { area length method, } \\
\text { LAA and pulmo- } \\
\text { nary veins were } \\
\text { excluded } \\
\text { No significant dif- } \\
\text { ference between } \\
\text { genders } \\
\text { The LA contractile } \\
\text { function increased } \\
\text { significantly with } \\
\text { age, while the LA } \\
\text { conduit function } \\
\text { decreased seen in } \\
\text { both volumetric } \\
\text { and deformation } \\
\text { techniques }\end{array}$ \\
\hline $\begin{array}{l}\text { Doria de Vascon- } \\
\text { cellos et al. } 2020 \\
\text { [106] }\end{array}$ & $\begin{array}{l}\mathrm{HV}(\mathrm{n}=228 \\
(91 \mathrm{M}, 137 \mathrm{~F})\end{array}$ & $64.7 \pm 8.1$ & $\begin{array}{l}\text { CMR } 1.5 \mathrm{~T} \\
\text { (Multimodality } \\
\text { feature track- } \\
\text { ing version 6.0, } \\
\text { Toshiba) }\end{array}$ & $\begin{array}{l}\text { Volumetric }(\%) \text { : } \\
\text { Total EF } \\
\text { Passive EF } \\
\text { Active EF } \\
\text { Strain }(\%) \text { : } \\
\text { Reservoir Strain } \\
\text { Contractile Strain } \\
\text { Strain rate }\left(\mathrm{s}^{-1}\right) \text { : } \\
\text { Reservoir SR } \\
\text { Conduit SR } \\
\text { Contractile SR }\end{array}$ & $\begin{array}{l}59.5 \pm 10.5 \\
28.2 \pm 8.7 \\
44 \pm 11.3 \\
32.6 \pm 14.2 \\
19.2 \pm 9.1 \\
1.6 \pm 0.8 \\
-1.6 \pm 0.9 \\
-2.1 \pm 1.0\end{array}$ & $\begin{array}{l}\text { From Multiethnic } \\
\text { Study of Athero- } \\
\text { sclerosis } \\
\text { Volumetric by biplane } \\
\text { area length method, } \\
\text { LAA and pulmo- } \\
\text { nary veins were } \\
\text { excluded } \\
\text { Images with poor } \\
\text { tracking and/or } \\
\text { foreshortened were } \\
\text { excluded, no spe- } \\
\text { cific number stated } \\
\text { No conduit strain } \\
\text { No ethnicity com- } \\
\text { parison }\end{array}$ \\
\hline
\end{tabular}

bSSFP: Balanced Steady State Free Precession, BTFE: Balanced Turbo Field Echo, FT: feature tracking, $H V$ : healthy volunteers, $L A A$ : left atrial appendage, $E F$ : emptying fraction, $\mathrm{SR}=$ strain rate

Fig. 3 Normal values of LA phasic function by strain analysis. Table illustrates normal ranges by TTE vs CMR for: LAS_r $=$ LA strain at reservoir, LAS_cd $=$ LA strain at conduit, LAS_bp = LA strain at booster-pump phase. Normal ranges from[64, 68, 105, 106]. The graph illustrates the change in LA strain during the cardiac cycle

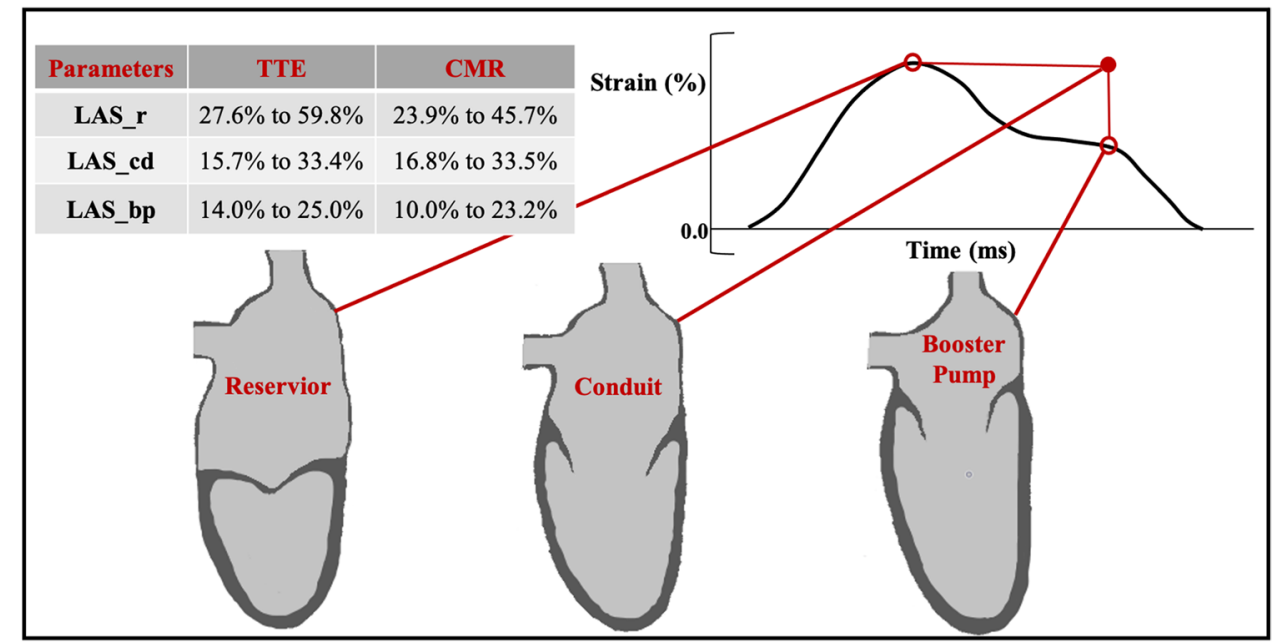




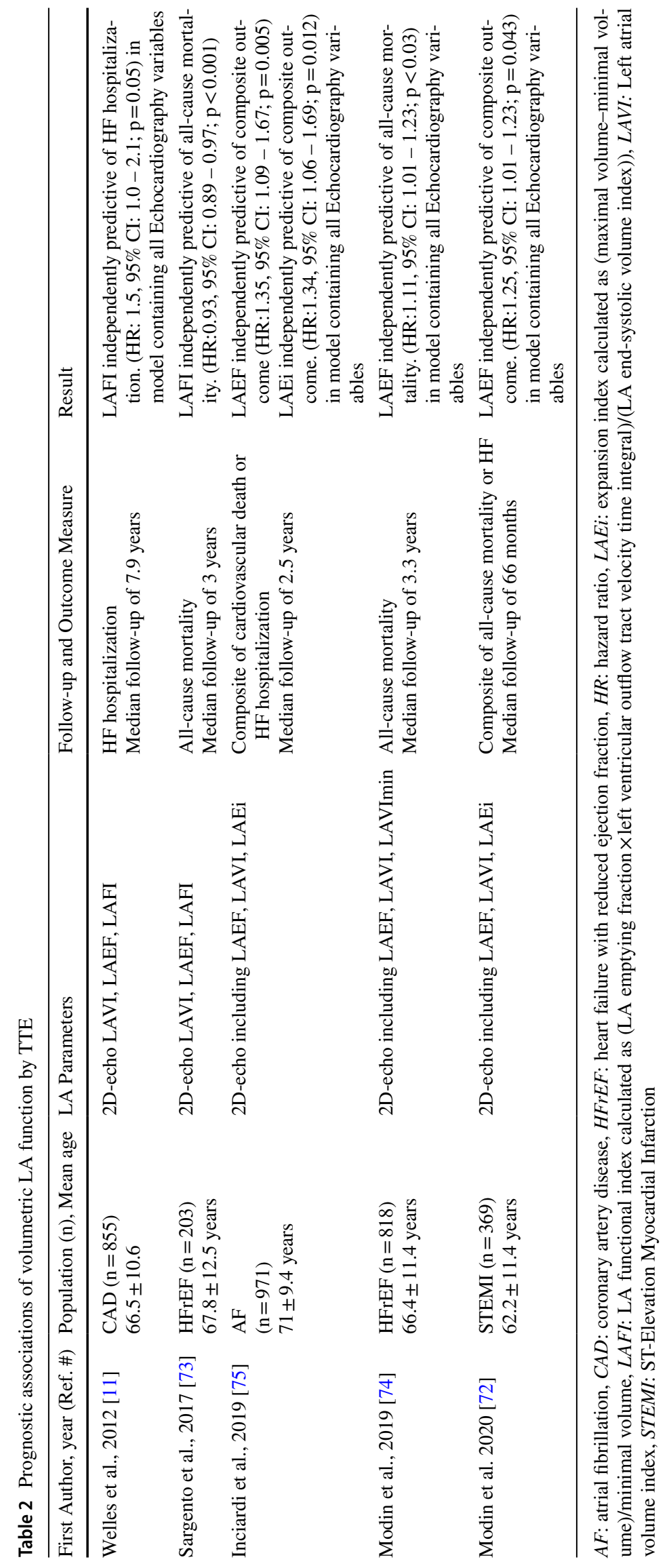


predicted AF incidence (HR 0.68, 95\% CI, 0.48-0.96) [77]. This prognostic utility has also been demonstrated in hypertrophic cardiomyopathy, where impaired LA reservoir strain $(<18 \%)$ significantly increased the risk of mortality and HF development or progression [89].

CMR studies focusing on the prognostic value of LASR are limited. Only one retrospective study with a small sample size $(n=30)$ showed an association between LASR during the conduit phase and the incidence of acute myocarditis, with a cut-off of $-1.6 \mathrm{~s}^{1-}$ showing $83 \%$ sensitivity and $80 \%$ specificity [90].

\section{LA function as potential therapeutic target}

LA function may be an important future therapeutic target and endpoint for clinical trials. A recent review summarised the mechanisms and the evaluation of LA remodelling [91], whilst another reported the relationship between LA remodelling and the development of AF and the therapeutic implications for LA remodelling reversal [92]. Studies have demonstrated LA reverse remodelling post-intervention, which was defined as an improvement in LA function [55, 93-95].

TTE-TDI has been used to demonstrate an improvement in LA contractile function post-cardioversion in AF of both short (1-6 months) [93] and chronic duration [94]. Following catheter ablation for AF, $63 \%$ of the patients demonstrated a decrease in LAV max (>15\%), accompanied by an improvement in LA longitudinal lengthening and LA shortening using TDI [96]. Similar results were reported in HF patients who underwent cardiac resynchronization therapy [95]. 2D-STE has also been utilised to assess the LA response post-intervention: LA reservoir and booster strain improved post-transcatheter aortic valve implantation at 3-month follow-up [55].

\section{LAS in guidelines}

Despite the advantages of strain and SR, their clinical application is limited due to measurement variability. This inconsistency is related to three main factors: imaging modality, software, and operator [60]. Thus, published recommendations and guidelines in disease diagnosis that include LAS are limited due to the need for technique validation. To our knowledge, only the European Association of Cardiovascular Imaging (EACVI) and the European Heart Rhythm Association (EHRA)Expert Consensus Document on the role of multi-modality imaging for the evaluation of patients with atrial fibrillation, comments that LA lateral wall strain can be reliably imaged and LA reservoir strain $<30 \%$ indicates significant alteration of LA reservoir function, which predicts poor outcome [97].

\section{Inter-modality agreement}

Studies that directly compare TTE and CMR in the context of LA functional assessment are limited, with the majority reporting correlation rather than agreement (Table 3). A study including 34 patients with permanent AF compared LA volumetric assessment using 2D-TTE with CMR [98]. The inter-modality correlation was moderate for volumes $(r=0.59$ for LAmax and $r=0.59$ for LAmin, $P<0.001$ ), while poor for LAEF $(r=0.34, P<0.05)$. However, the two scans were separated by $7 \pm 4$ days [98]. Another study in 54 patients post-myocardial infarction showed good intermodality correlation $(\mathrm{LAV} \min \mathrm{r}=0.70, \mathrm{LAV} \max \mathrm{r}=0.71$ ) when scans were performed on the same day [21], though the volumes were still under-estimated by TTE. Using 3D-TTE for LA volumetric assessment also underestimates LA volume compared to the biplane area length method by CMR [40]. Moreover, whilst TTE and CMR were conducted on the same day, the agreement between the two modalities was poor by Bland-Altman analysis: LAVmax: 19.7 (-42.0 to 81.5) and LAEF: -1.6 (-28.0 to 24.9).

A recent study on 43 patients with clinically indicated CMR scan and 11 healthy volunteers, compared LAS parameters by CMR and TTE. The comparison included 4 different post-processing image analysis software [99]. Overall, modest to excellent inter-modality correlation was seen, depending on which strain parameter was analysed (ICC >0.71). Reservoir and booster strain values by STE (TomTec) were significantly higher than by FT-CMR (Medis), while conduit strain values were not significantly different. Moreover, reservoir strain had the lowest inter- and intra-observer variability for both modalities [99]. To our knowledge, no studies have evaluated inter-modality correlation for LASR.

\section{Reproducibility of techniques}

Most studies assessing reproducibility of an imaging technique focus on inter- and intra- observer variability (Supplemental Table-1). Overall, LAS has lower inter- and intraobserver variability than LASR, and reservoir and conduit function have lower variability than booster function. However, whilst important, observer variability does not address variations in image acquisition and day-to-day physiological variation. Test-retest reproducibility of an imaging technique is fundamental for its validity and its use in longitudinal studies for monitoring disease progression or response to treatment. Studies evaluating the test-retest reproducibility of LA assessment have been limited and with small 


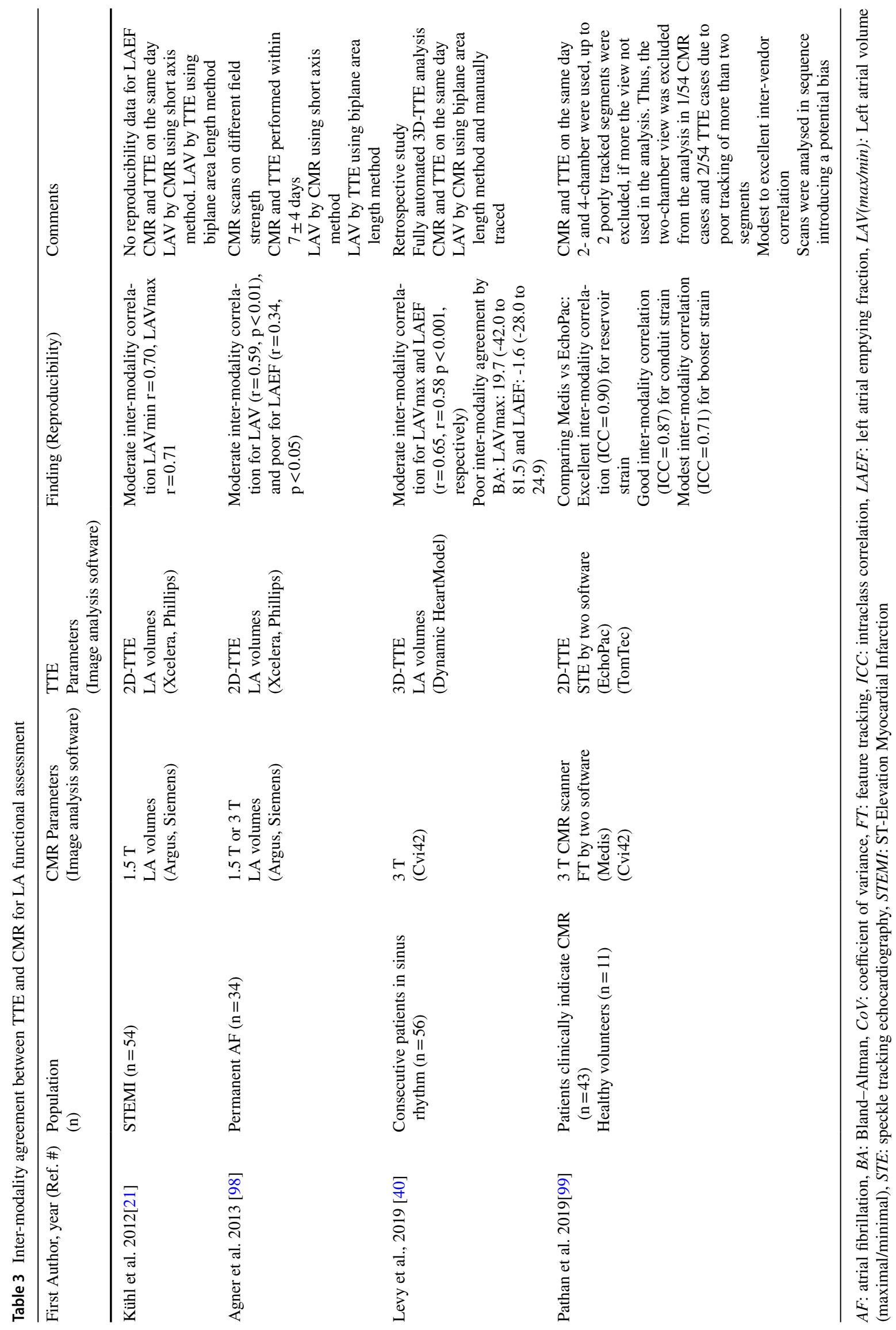




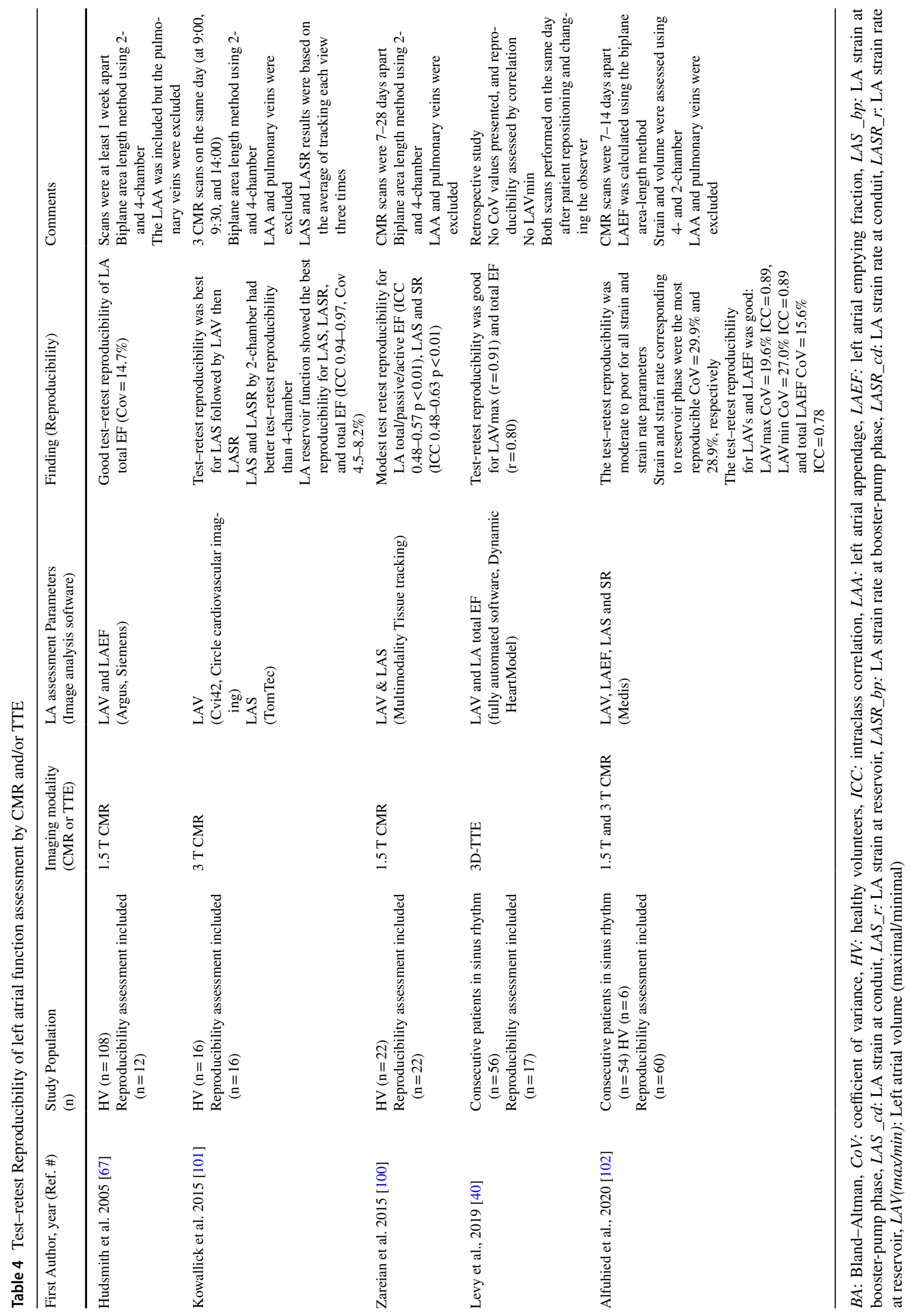


sample sizes $(n=12-22)$ and mainly in healthy volunteers [40, 67, 100, 101] (Table 4). However, a recent study including subjects with and without cardiovascular disease $(n=60)$ showed LAEF to have better test-retest reproducibility than LA strain, whilst reservoir strain accounted for the most reproducible strain parameter [102].

\section{Limitations of LA strain applications in clinical practise}

Whilst LA volumes are routinely used in clinical practice, LA volumetric assessment has some limitations in assessing subclinical cardiac dysfunction, due to their lower sensitivity in assessing subtle changes and their lack of representation of myocardial contractility, as they are load-dependent measurements [103]. For LAS analysis, the anatomical characteristics of the LA, such as the thin walls and the presence of the LA appendage and pulmonary veins, make it challenging to trace the LA endocardial borders. Also, there isn't a universal and routinely available dedicated image analysis software for LA strain analysis, and more importantly, there is a need for standardization of techniques and establishment of 'normal' cut-offs for the various parameters, before routine clinical application.

\section{Conclusions}

The LA plays a vital role in maintaining normal cardiac function. Accurate LA assessment is imperative in understanding the pathophysiology of cardiovascular disease. We have reviewed the conventional and novel imaging techniques available for its assessment. Whilst these are promising and provide important insights into disease progression and add prognostic value in many conditions, there are limitations in the accurate quantification of LA function. Comparing the test-retest reproducibility of LA function assessment techniques between modalities should ideally be performed in the same cohort, in order to establish the technique with the best discriminative ability for detecting clinically relevant changes with repeated measurements.

Supplementary Information The online version contains supplementary material available at https://doi.org/10.1007/s10554-021-02316-x.

Author contributions We confirm that all authors have participated in the work and have reviewed the final manuscript before submission.

\section{Declarations}

Conflict of interest The authors declare that they have no conflict of interest to disclose.
Open Access This article is licensed under a Creative Commons Attribution 4.0 International License, which permits use, sharing, adaptation, distribution and reproduction in any medium or format, as long as you give appropriate credit to the original author(s) and the source, provide a link to the Creative Commons licence, and indicate if changes were made. The images or other third party material in this article are included in the article's Creative Commons licence, unless indicated otherwise in a credit line to the material. If material is not included in the article's Creative Commons licence and your intended use is not permitted by statutory regulation or exceeds the permitted use, you will need to obtain permission directly from the copyright holder. To view a copy of this licence, visit http://creativecommons.org/licenses/by/4.0/.

\section{References}

1. Yancy CW, Jessup M, Bozkurt B et al. 2017 ACC/AHA/HFSA Focused Update of the 2013 ACCF/AHA Guideline for the Management of Heart Failure: A Report of the American College of Cardiology/American Heart Association Task Force on Clinical Practice Guidelines and the Heart Failure Society of America. 136:e137-e161.

2. Ponikowski P, Voors AA, Anker SD et al (2016) 2016 ESC guidelines for the diagnosis and treatment of acute and chronic heart failure: the task force for the diagnosis and treatment of acute and chronic heart failure of the European Society of Cardiology (ESC)Developed with the special contribution of the Heart Failure Association (HFA) of the ESC. Eur Heart J 37:2129-2200

3. Tsang TS, Abhayaratna WP, Barnes ME et al (2006) Prediction of cardiovascular outcomes with left atrial size: is volume superior to area or diameter? J Am Coll Cardiol 47:1018-1023

4. Poulsen MK, Dahl JS, Henriksen JE et al (2013) Left atrial volume index: relation to long-term clinical outcome in type 2 diabetes. J Am Coll Cardiol 62:2416-2421

5. Khan MA, Yang EY, Zhan Y et al (2019) Association of left atrial volume index and all-cause mortality in patients referred for routine cardiovascular magnetic resonance: a multicenter study. J Cardiovasc Magn Reson 21:4

6. Rusinaru D, Bohbot Y, Kowalski C, Ringle A, Maréchaux S, Tribouilloy C (2017) Left atrial volume and mortality in patients with aortic stenosis. J Am Heart Assoc 6:e006615

7. Nagueh SF, Smiseth OA, Appleton CP et al (2016) Recommendations for the evaluation of left ventricular diastolic function by echocardiography: an update from the American society of echocardiography and the European association of cardiovascular imaging. J Am Soc Echocardiogr 29:277-314

8. Paulus WJ, Tschöpe C, Sanderson JE et al (2007) How to diagnose diastolic heart failure: a consensus statement on the diagnosis of heart failure with normal left ventricular ejection fraction by the Heart Failure and Echocardiography Associations of the European Society of Cardiology. Eur Heart J 28:2539-2550

9. Habibi M, Chahal H, Opdahl A et al (2014) Association of CMRmeasured LA function with heart failure development: results from the MESA study. JACC Cardiovasc Imaging 7:570-579

10. Pieske B, Tschöpe C, de Boer RA et al (2019) How to diagnose heart failure with preserved ejection fraction: the HFA-PEFF diagnostic algorithm: a consensus recommendation from the Heart Failure Association (HFA) of the European Society of Cardiology (ESC). Eur Heart J 40:3297-3317

11. Welles CC, Ku IA, Kwan DM, Whooley MA, Schiller NB, Turakhia MP (2012) Left atrial function predicts heart failure hospitalization in subjects with preserved ejection fraction and coronary heart disease: longitudinal data from the heart and soul study. J Am Coll Cardiol 59:673-680 
12. Kanagala P, Arnold JR, Cheng ASH et al (2020) Left atrial ejection fraction and outcomes in heart failure with preserved ejection fraction. Int J Cardiovasc Imaging 36:101-110

13. Kanagala P, Arnold JR, Singh A et al (2020) Intra-study and inter-technique validation of cardiovascular magnetic resonance imaging derived left atrial ejection fraction as a prognostic biomarker in heart failure with preserved ejection fraction. Int J Cardiovasc Imaging 36(5):921-928

14. Pellicori P, Zhang J, Lukaschuk E et al (2014) Left atrial function measured by cardiac magnetic resonance imaging in patients with heart failure: clinical associations and prognostic value. Eur Heart J 36:733-742

15. Hoit BD (2018) Assessment of left atrial function by echocardiography: novel insights. Curr Cardiol Rep 20:96

16. Leung DY, Boyd A, Ng AA, Chi C, Thomas L (2008) Echocardiographic evaluation of left atrial size and function: Current understanding, pathophysiologic correlates, and prognostic implications. Am Heart J 156:1056-1064

17. Kurt M, Wang J, Torre-Amione G, Nagueh SF (2009) Left atrial function in diastolic heart failure. Circ Cardiovasc Imaging $2: 10-15$

18. Hoit BD (2014) Left atrial size and function: role in prognosis. J Am Coll Cardiol 63:493-505

19. Muranaka A, Yuda S, Tsuchihashi K et al (2009) Quantitative assessment of left ventricular and left atrial functions by strain rate imaging in diabetic patients with and without hypertension. Echocardiography 26:262-271

20. Lang RM, Badano LP, Mor-Avi V et al (2015) Recommendations for cardiac chamber quantification by echocardiography in adults: an update from the American society of echocardiography and the European association of cardiovascular imaging. J Am Soc Echocardiogr 28:1-39.e14

21. Kühl JT, Lønborg J, Fuchs A et al (2012) Assessment of left atrial volume and function: a comparative study between echocardiography, magnetic resonance imaging and multi slice computed tomography. Int J Cardiovasc Imaging 28:1061-1071

22. Szilveszter B, Nagy AI, Vattay B et al (2020) Left ventricular and atrial strain imaging with cardiac computed tomography: validation against echocardiography. J Cardiovasc Comput Tomogr 14:363-369

23. Olsen FJ, Bertelsen L, de Knegt MC et al (2016) Multimodality cardiac imaging for the assessment of left atrial function and the association with atrial arrhythmias. Circ Cardiovasc Imaging 9:e004947

24. Genovese D, Singh A, Volpato V et al (2018) Load dependency of left atrial strain in normal subjects. J Am Soc Echocardiogr 31:1221-1228

25. Singh A, Addetia K, Maffessanti F, Mor-Avi V, Lang RM (2017) LA strain for categorization of lv diastolic dysfunction. JACC Cardiovasc Imaging 10:735-743

26. Suga H (1974) Importance of atrial compliance in cardiac performance. Circ Res 35:39-43

27. Pagel PS, Kehl F, Gare M, Hettrick DA, Kersten JR, Warltier DC (2003) Mechanical function of the left atrium: new insights based on analysis of pressure-volume relations and doppler echocardiography. Anesthesiology 98:975-994

28. Yamaguchi M, Arakawa M, Tanaka T, Takaya T, Nagano T, Hirakawa S (1987) Study on left atrial contractile performance-participation of Frank-Starling mechanism. Jpn Circ J 51:1001-1009

29. Stefanadis C, Dernellis J, Toutouzas P (2001) A clinical appraisal of left atrial function. Eur Heart J 22:22-36

30. Barbier P, Solomon SB, Schiller NB, Glantz SA (1999) Left atrial relaxation and left ventricular systolic function determine left atrial reservoir function. Circulation 100:427-436
31. Toma Y, Matsuda Y, Moritani K, Ogawa H, Matsuzaki M, Kusukawa R (1987) Left atrial filling in normal human subjects: relation between left atrial contraction and left atrial early filling. Cardiovasc Res 21:255-259

32. Eshoo S, Ross David L, Thomas L (2009) Impact of mild hypertension on left atrial size and function. Circ Cardiovasc Imaging 2:93-99

33. Tan YT, Wenzelburger F, Lee E et al (2010) Reduced left atrial function on exercise in patients with heart failure and normal ejection fraction. Heart 96:1017

34. Mehrzad R, Rajab M, Spodick DH (2014) The three integrated phases of left atrial macrophysiology and their interactions. Int J Mol Sci 15:15146-15160

35. Boudoulas KD, Paraskevaidis IA, Boudoulas H, Triposkiadis FK (2014) The left atrium: from the research laboratory to the clinic. Cardiology 129:1-17

36. Patel DA, Lavie CJ, Milani RV, Shah S, Gilliland Y (2009) Clinical implications of left atrial enlargement: a review. Ochsner J 9:191-196

37. Sun H, Gaspo R, Leblanc N, Nattel S (1998) Cellular mechanisms of atrial contractile dysfunction caused by sustained atrial tachycardia. Circulation 98:719-727

38. Li L, Deng Y-B, Guo L-D, Liu K, Zhang J, Tang Q-Y (2020) Evaluation of long-term impact of pericardiectomy on left atrial functions in patients with constrictive pericarditis using speckle tracking echocardiography. Ultrasound Med Biol 46:1158-1168

39. Zhu S, Sun W, Qiao W et al (2020) Real time three-dimensional echocardiographic quantification of left atrial volume in orthotopic heart transplant recipients: comparisons with cardiac magnetic resonance imaging. Echocardiography 37:1243-1250

40. Levy F, Iacuzio L, Schouver ED et al (2019) Performance of a new fully automated transthoracic three-dimensional echocardiographic software for quantification of left cardiac chamber size and function: comparison with 3 Tesla cardiac magnetic resonance. J Clin Ultrasound 47:546-554

41. Hudsmith LE, Cheng AS, Tyler DJ et al (2007) Assessment of left atrial volumes at 1.5 Tesla and 3 Tesla using FLASH and SSFP cine imaging. J Cardiovasc Magn Reson 9(4):673-679

42. Souto Nacif M, Dias Barranhas A, Türkbey E et al (2013) Left atrial volume quantification using cardiac MRI in atrial fibrillation: comparison of the Simpson's method with biplane arealength, ellipse, and three-dimensional methods. Diagn Interv Radiol 19:213-220

43. Sievers B, Kirchberg S, Addo M, Bakan A, Brandts B, Trappe HJ (2004) Assessment of left atrial volumes in sinus rhythm and atrial fibrillation using the biplane area-length method and cardiovascular magnetic resonance imaging with TrueFISP. J Cardiovasc Magn Reson 6:855-863

44. Aung SM, Güler A, Güler Y, Huraibat A, Karabay CY, Akdemir I (2017) Left atrial strain in heart failure with preserved ejection fraction. Herz 42:194-199

45. Fan JL, Su B, Zhao X et al (2020) Correlation of left atrial strain with left ventricular end-diastolic pressure in patients with normal left ventricular ejection fraction. Int J Cardiovasc Imaging 36:1659-1666

46. Mondillo S, Cameli M, Caputo ML et al (2011) Early detection of left atrial strain abnormalities by speckle-tracking in hypertensive and diabetic patients with normal left atrial size. J Am Soc Echocardiogr 24:898-908

47. Singh A, Medvedofsky D, Mediratta A et al (2019) Peak left atrial strain as a single measure for the non-invasive assessment of left ventricular filling pressures. Int J Cardiovasc Imaging 35:23-32 
48. Meimoun P, Djebali M, Botoro T et al (2019) Left atrial strain and distensibility in relation to left ventricular dysfunction and prognosis in aortic stenosis. Echocardiography 36:469-477

49. Modin D, Biering-Sørensen SR, Møgelvang R, Alhakak AS, Jensen JS, Biering-Sørensen T (2019) Prognostic value of left atrial strain in predicting cardiovascular morbidity and mortality in the general population. Eur Heart J Cardiovasc Imaging 20:804-815

50. Vasquez N, Ostrander BT, Lu D-Y et al (2019) Low left atrial strain is associated with adverse outcomes in hypertrophic cardiomyopathy patients. J Am Soc Echocardiogr 32:593-603.e1

51. Potter EL, Ramkumar S, Kawakami H et al (2020) Association of asymptomatic diastolic dysfunction assessed by left atrial strain with incident heart failure. JACC Cardiovasc Imaging 13:2316-2326

52. Shaikh AY, Maan A, Khan UA et al (2012) Speckle echocardiographic left atrial strain and stiffness index as predictors of maintenance of sinus rhythm after cardioversion for atrial fibrillation: a prospective study. Cardiovasc Ultrasound 10:48-48

53. Costa C, González-Alujas T, Valente F et al (2016) Left atrial strain: a new predictor of thrombotic risk and successful electrical cardioversion. Echo research and practice 3:45-52

54. Cameli M, Lisi M, Reccia R et al (2014) Pre-operative left atrial strain predicts post-operative atrial fibrillation in patients undergoing aortic valve replacement for aortic stenosis. Int J Cardiovasc Imaging 30:279-286

55. D’Ascenzi F, Cameli M, Henein M et al (2013) Left atrial remodelling in patients undergoing transcatheter aortic valve implantation: a speckle-tracking prospective, longitudinal study. Int J Cardiovasc Imaging 29:1717-1724

56. Yip G, Abraham T, Belohlavek M, Khandheria BK (2003) Clinical applications of strain rate imaging. J Am Soc Echocardiogr 16:1334-1342

57. Marwick TH (2006) Measurement of strain and strain rate by echocardiography: ready for prime time? J Am Coll Cardiol 47:1313-1327

58. Zhang Q, Yip GWK, Yu CM (2008) Approaching regional left atrial function by tissue Doppler velocity and strain imaging. EP Europace 10(3):62-69

59. Hatle L, Sutherland GR (2000) Regional myocardial function-a new approach. Eur Heart J 21:1337-1357

60. Amzulescu MS, De Craene M, Langet H et al (2019) Myocardial strain imaging: review of general principles, validation, and sources of discrepancies. Eur Heart J Cardiovasc Imaging 20:605-619

61. Badano LP, Kolias TJ, Muraru D et al (2018) Standardization of left atrial, right ventricular, and right atrial deformation imaging using two-dimensional speckle tracking echocardiography: a consensus document of the EACVI/ASE/Industry Task Force to standardize deformation imaging. Eur Heart J Cardiovasc Imaging 19:591-600

62. Van Berendoncks AM, Van Gaal L, De Block C et al (2019) Abnormal longitudinal peak systolic strain in asymptomatic patients with type I diabetes mellitus. Echocardiography $36: 478-485$

63. Sugimoto T, Robinet S, Dulgheru R et al (2018) Echocardiographic reference ranges for normal left atrial function parameters: results from the EACVI NORRE study. Eur Heart J: Cardiovasc Imaging 19:630-638

64. Pathan F, D'Elia N, Nolan MT, Marwick TH, Negishi K (2017) Normal ranges of left atrial strain by speckle-tracking echocardiography: a systematic review and meta-Analysis. J Am Soc Echocardiogr 30:59-70.e8

65. Morris DA, Takeuchi M, Krisper M et al (2014) Normal values and clinical relevance of left atrial myocardial function analysed by speckle-tracking echocardiography: multicentre study. Eur Heart J: Cardiovasc Imaging 16:364-372

66. Maceira AM, Cosin-Sales J, Prasad SK, Pennell DJ (2016) Characterization of left and right atrial function in healthy volunteers by cardiovascular magnetic resonance. J Cardiovasc Magn Reson 18:64

67. Hudsmith LE, Petersen SE, Francis JM, Robson MD, Neubauer S (2005) Normal human left and right ventricular and left atrial dimensions using steady state free precession magnetic resonance imaging. J Cardiovasc Magn Reson 7:775-782

68. Truong VT, Palmer C, Wolking S et al (2019) Normal left atrial strain and strain rate using cardiac magnetic resonance feature tracking in healthy volunteers. Eur Heart J Cardiovasc Imaging 21:446-453

69. Rossi A, Cicoira M, Bonapace S et al (2007) Left atrial volume provides independent and incremental information compared with exercise tolerance parameters in patients with heart failure and left ventricular systolic dysfunction. Heart 93:1420-1425

70. Rossi A, Cicoira M, Zanolla L et al (2002) Determinants and prognostic value of left atrial volume in patients with dilated cardiomyopathy. J Am Coll Cardiol 40:1425

71. Rossi A, Temporelli PL, Quintana M et al (2009) Independent relationship of left atrial size and mortality in patients with heart failure: an individual patient meta-analysis of longitudinal data (MeRGE Heart Failure). Eur J Heart Fail 11:929-936

72. Modin D, Pedersen S, Fritz-Hansen T, Gislason G, BieringSØRensen TOR (2020) Left atrial function determined by echocardiography predicts incident heart failure in patients with stemi treated by primary percutaneous coronary intervention. J Card Fail 26:35-42

73. Sargento L, Vicente Simões A, Longo S, Lousada N, Palma Dos Reis R (2017) Left atrial function index predicts long-term survival in stable outpatients with systolic heart failure. Eur Heart J Cardiovasc Imaging 18:119-127

74. Modin D, Sengeløv M, Jørgensen PG et al (2019) Prognostic value of left atrial functional measures in heart failure with reduced ejection fraction. J Card Fail 25:87-96

75. Inciardi RM, Giugliano RP, Claggett B et al (2019) Left atrial structure and function and the risk of death or heart failure in atrial fibrillation. Eur J Heart Fail 21:1571-1579

76. Gupta S, Matulevicius SA, Ayers CR et al (2013) Left atrial structure and function and clinical outcomes in the general population. Eur Heart J 34:278-285

77. Habibi M, Samiei S, Ambale Venkatesh B et al (2016) Cardiac Magnetic Resonance-Measured Left Atrial Volume and Function and Incident Atrial Fibrillation. Circ Cardiovasc Imaging 9:e004299

78. Kaminski M, Steel K, Jerosch-Herold M et al (2011) Strong cardiovascular prognostic implication of quantitative left atrial contractile function assessed by cardiac magnetic resonance imaging in patients with chronic hypertension. J Cardiovasc Magn Reson 13:42

79. Lin J, Ma H, Gao L et al (2020) Left atrial reservoir strain combined with E/E' as a better single measure to predict elevated LV filling pressures in patients with coronary artery disease. Cardiovasc Ultrasound 18:11

80. Magne J, Cosyns B, Popescu BA et al (2019) Distribution and prognostic significance of left ventricular global longitudinal strain in asymptomatic significant aortic stenosis: an individual participant data meta-analysis. JACC Cardiovasc Imaging 12:84-92

81. Cameli M, Sciaccaluga C, Mandoli GE, D’Ascenzi F, Tsioulpas C, Mondillo S (2019) The role of the left atrial function in the surgical management of aortic and mitral valve disease. Echocardiography 36:1559-1565 
82. Cameli M, Lisi M, Focardi M et al (2012) Left Atrial deformation analysis by speckle tracking echocardiography for prediction of cardiovascular outcomes. Am J Cardiol 110:264-269

83. Al Saikhan L, Hughes AD, Chung WS, Alsharqi M, Nihoyannopoulos P (2019) Left atrial function in heart failure with mid-range ejection fraction differs from that of heart failure with preserved ejection fraction: a 2D speckle-tracking echocardiographic study. Eur Heart J Cardiovasc Imaging 20:279-290

84. Santos ABS, Kraigher-Krainer E, Gupta DK et al (2014) Impaired left atrial function in heart failure with preserved ejection fraction. Eur J Heart Fail 16:1096-1103

85. Freed BH, Daruwalla V, Cheng JY et al (2016) Prognostic utility and clinical significance of cardiac mechanics in heart failure with preserved ejection fraction. Circ Cardiovasc Imaging 9:e003754

86. Santos ABS, Roca GQ, Claggett B et al (2016) Prognostic relevance of left atrial dysfunction in heart failure with preserved ejection fraction. Circ Heart Fail 9:e002763

87. Bytyçi I, Dini FL, Bajraktari A et al (2020) Speckle trackingderived left atrial stiffness predicts clinical outcome in heart failure patients with reduced to mid-range ejection fraction. Clin Med (Northfield Il) 9:1244

88. Porpáczy A, Nógrádi Á, Vértes V et al (2019) Left atrial stiffness is superior to volume and strain parameters in predicting elevated NT-proBNP levels in systemic sclerosis patients. Int J Cardiovasc Imaging 35:1795-1802

89. Hinojar R, Zamorano JL, Fernández-Méndez MA et al (2019) Prognostic value of left atrial function by cardiovascular magnetic resonance feature tracking in hypertrophic cardiomyopathy. Int J Cardiovasc Imaging 35:1055-1065

90. Dick A, Schmidt B, Michels G, Bunck AC, Maintz D, Baessler B (2017) Left and right atrial feature tracking in acute myocarditis: a feasibility study. Eur J Radiol 89:72-80

91. Thomas L, Abhayaratna WP (2017) Left atrial reverse remodeling. JACC Cardiovasc Imaging 10:65

92. Casaclang-Verzosa G, Gersh BJ, Tsang TS (2008) Structural and functional remodeling of the left atrium: clinical and therapeutic implications for atrial fibrillation. J Am Coll Cardiol 51:1-11

93. Sanders P, Morton JB, Kistler PM, Vohra JK, Kalman JM, Sparks PB (2003) Reversal of atrial mechanical dysfunction after cardioversion of atrial fibrillation. Circulation 108:1976-1984

94. Thomas L, McKay T, Byth K, Marwick TH (2007) Abnormalities of left atrial function after cardioversion: an atrial strain rate study. Heart 93:89

95. Donal E, Tan K, Leclercq C et al (2009) Left atrial reverse remodeling and cardiac resynchronization therapy for chronic heart failure patients in sinus rhythm. J Am Soc Echocardiogr 22:1152-1158
96. Tops LF, Delgado V, Bertini M et al (2011) Left atrial strain predicts reverse remodeling after catheter ablation for atrial fibrillation. J Am Coll Cardiol 57:324

97. Donal E, Lip GYH, Galderisi M et al (2016) EACVI/EHRA expert consensus document on the role of multi-modality imaging for the evaluation of patients with atrial fibrillation. Eur Heart J Cardiovasc Imaging 17:355-383

98. Agner BFR, Kühl JT, Linde JJ et al (2013) Assessment of left atrial volume and function in patients with permanent atrial fibrillation: comparison of cardiac magnetic resonance imaging, 320-slice multi-detector computed tomography, and transthoracic echocardiography. Eur Heart J Cardiovasc Imaging 15:532-540

99. Pathan F, Zainal Abidin HA, Vo QH et al (2021) Left atrial strain: a multi-modality, multi-vendor comparison study. Eur Heart J Cardiovasc Imaging 22:102-110

100. Zareian M, Ciuffo L, Habibi M et al (2015) Left atrial structure and functional quantitation using cardiovascular magnetic resonance and multimodality tissue tracking: validation and reproducibility assessment. J Cardiovasc Magn Reson 17:52

101. Kowallick JT, Morton G, Lamata P et al (2015) Quantification of atrial dynamics using cardiovascular magnetic resonance: interstudy reproducibility. J Cardiovasc Magn Reson 17:36-36

102. Alfuhied A, Marrow BA, Elfawal S et al (2020) Reproducibility of left atrial function using cardiac magnetic resonance imaging. Eur Radiol 41(2):1-10

103. Sanderson JE, Fraser AG (2006) Systolic dysfunction in heart failure with a normal ejection fraction: echo-doppler measurements. Prog Cardiovasc Dis 49:196-206

104. Petersen SE, Aung N, Sanghvi MM et al (2017) Reference ranges for cardiac structure and function using cardiovascular magnetic resonance (CMR) in Caucasians from the UK Biobank population cohort. J Cardiovasc Magn Reson 19:18

105. Peng J, Zhao X, Zhao L et al (2018) Normal values of myocardial deformation assessed by cardiovascular magnetic resonance feature tracking in a healthy chinese population: a multicenter study. Front Physiol 9:1181

106. Doria de Vasconcellos H, Win TT, Chamera E et al (2020) References values for left atrial volumes, emptying fractions, strains, and strain rates and their determinants by age, gender, and ethnicity: the multiethnic study of atherosclerosis (MESA). Acad Radiol 28(3):356-363

Publisher's Note Springer Nature remains neutral with regard to jurisdictional claims in published maps and institutional affiliations. 